\title{
Determination of Nanogram Quantities of Emodin in Pharmaceutical Preparations and Biofluids by Luminol-Myoglobin Chemiluminescence System
}

\author{
Yun Zhang, ${ }^{1}$ Xili He, ${ }^{1,2}$ and Zhenghua Song ${ }^{1}$ \\ ${ }^{1}$ Key Laboratory of Synthetic and Natural Functional Molecule Chemistry of Ministry of Education, \\ College of Chemistry \& Material Science, Northwest University, Xi'an 710069, China \\ ${ }^{2}$ School of Science, Xi'an Jiaotong University, Xi'an 710049, China \\ Correspondence should be addressed to Zhenghua Song, songzhenghua@ hotmail.com \\ Copyright (C) 2012 Yun Zhang et al. This is an open access article distributed under the Creative Commons Attribution License, \\ which permits unrestricted use, distribution, and reproduction in any medium, provided the original work is properly cited.
}

\begin{abstract}
Based on the quenching effect of emodin on the luminol-myoglobin (Mb) reaction, a sensitive method for the determination of nanogram level emodin by flow injection chemiluminescence (FI-CL) is presented for the first time. It was found that the CL intensity from luminol-Mb system could be inhibited in the presence of emodin, and the decrement of CL intensity was linearly proportional to the logarithm of emodin concentration in the range of $0.5-300 \mathrm{ng} \cdot \mathrm{mL}^{-1}(R=0.9956)$ with the detection limit of $0.2 \mathrm{ng} \cdot \mathrm{mL}^{-1}(3 \sigma)$. At a flow rate of $2.0 \mathrm{~mL} \cdot \mathrm{min}^{-1}$, a complete determination of emodin, including sampling and washing, could be accomplished in $0.5 \mathrm{~min}$ with the relative standard deviations (RSDs) of less than $3.5 \%$ ( $n=$ 5). The proposed method was successfully applied to the determination of emodin in pharmaceutical preparations and human serum samples. The possible CL mechanism of luminol-Mb-emodin reaction was explained.
\end{abstract}

Keywords: Emodin, luminol, myoglobin, chemiluminescence, serum, flow injection

\section{Introduction}

Natural ingredients that have been used traditionally to treat many diseases for hundreds of years are considered as a good choice for carcinoma therapy [1]. Emodin (1, 3, 8-trihydroxy-6methylanthraquinone, Figure $1, \mathrm{MW}=270$ ), one of the most commonly used species, comes from dry roots of rhubarb which is a group of plants that belongs to the genus rheum in the polygonaceae family. Emodin has been extensively researched for its traditional pharmacological effects, mainly in the treatment of constipation and menoxenia, skin burn, gallstone, hepatitis, inflammation, and osteomyelitis [2, 3]. Recently, a number of studies have placed emodin back into the attention focused on its anticancer activities against several types of cancer cells and virus, for instance, inhibiting ATPinduced macrophage death [4], mediating cytotoxicity in human nonsmall cell lung cancer cells [5], inducing resensitization of lung cancer cells to anoikis [6], against $\beta$-amyloid-induced neurotoxicity, 
<smiles>Cc1cc(O)c2c(c1)C(=O)c1cc(O)cc(O)c1C2=O</smiles>

Figure 1: Schematic diagram of emodin structure.

herpes simplex virus, human chronic myelocytic leukemia K562 cell lines [7-9], and inhibiting the growth of hepatoma cells [10].

The different methods for the determination of emodin have been reported, including highperformance liquid chromatography (HPLC) [11, 12], capillary electrophoresis (CE) [13], ultraperformance liquid chromatography-tandem mass spectrometry (UPLC-MS/MS) [14], electrochemistry (EC) [15], UV-Vis spectrophotometry [16], and electrochemiluminescence (ECL) [17, 18]. However, there was no report on the determination of emodin using flow injection chemiluminescence (FI-CL) up to now.

It has been reported that $\mathrm{Mb}$, which contains a single iron protoporphyrin or heme moiety in the ferric state $\mathrm{Mb}\left(\mathrm{Fe}^{\mathrm{III}}\right)$, can react with luminol yielding $\mathrm{CL}$ emission $[19,20]$. In this paper, it was found that the CL intensity from luminol-Mb system could be inhibited in the presence of emodin, and the decrement of CL intensity was linearly proportional to the logarithm of emodin concentration in the range of $0.5-300 \mathrm{ng} \cdot \mathrm{mL}^{-1}(R=0.9956)$ with the relative standard deviations (RSDs) of less than $3.5 \%(n=7)$. The simple and rapid method was successfully applied to the determination of emodin in pharmaceutical preparations and human serum samples.

\section{Experimental Section}

\subsection{Apparatus and Reagents}

The experiment instrument was flow injection CL analyzer (model IFFL-DD, Xi' an Remax Electronic Science-Tech. Co. Ltd); PTFE tubing (1.0 mm i.d.) was used as connection material in the flow system; luminol was used as supplied to prepare a $2.5 \times 10^{-2} \mathrm{~mol} \cdot \mathrm{L}^{-1}$ stock standard solution by dissolving $0.44 \mathrm{~g}$ luminol (Fluka, Biochemika) in $0.1 \mathrm{~mol} \cdot \mathrm{L}^{-1}$ sodium hydroxide in a $100 \mathrm{~mL}$ calibrated flask; horse heart $\mathrm{Mb}$ (Sigma) was purchased from local market and used as received without further purification. All reagents were of analytical purity grade. Doubly distilled water purified in a Milli-Q system (Millipore, Bedford, MA) was used throughout.

\subsection{Procedures}

The flow injection system used in this work was shown in Figure 2. A peristaltic pump was used to pump each of all flow streams at a flow rate of $2.0 \mathrm{~mL} \cdot \mathrm{min}^{-1}$. The carrier used in flow injection system was water. Luminol was used as supplied to prepare a $2.5 \times 10^{-5} \mathrm{~mol} \cdot \mathrm{L}^{-1}$ solution, and $\mathrm{NaOH}$ solution 


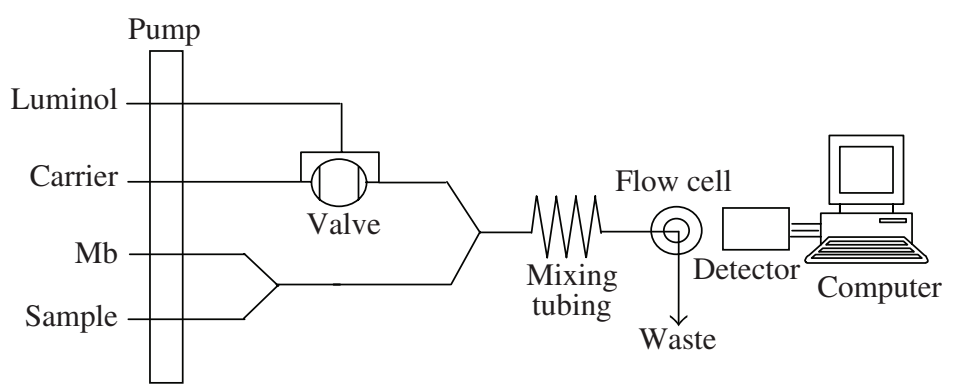

Figure 2: Schematic diagram of the present FI-CL system. Flow rate: $2.0 \mathrm{~mL} \cdot \mathrm{min}^{-1}$; high voltage: $-750 \mathrm{~V}$.

was $2.5 \times 10^{-2} \mathrm{~mol} \cdot \mathrm{L}^{-1}$. A six-way valve with loop of $100 \mu \mathrm{L}$ was used for luminol after a stable baseline was recorded, the CL signal produced in the CL emission cell when mixed with $\mathrm{Mb}$. The mixed solution was delivered into the CL cell, producing CL emission, and detected by the photomultiplier tube (PMT). The concentration of emodin could be quantified on the basis of the decrement of CL intensity, $\Delta I=I_{O}-I_{s}$, where $I_{s}$ and $I_{O}$ were CL signals in the presence and in the absence of emodin, respectively.

\subsection{Sample Preparation}

Five tablets of SANHUANG PIAN (produced by Shanxi Yabao Pharmaceutical Group Industry. Co. Ltd.) were weighed and ground to fine powder using a pestle and mortar and then homogenized; a sample equivalent to approximately $425 \pm 10 \mathrm{mg}$ of emodin was weighed accurately and dissolved in some ethanol and then diluted with doubly deionized water in a calibrated flask and ultrasound for 10 minutes. The solution was filtered by an ordinary filter paper, and suitable filtrate aliquots from this solution were diluted to an emodin concentration within the calibration range.

\section{Results and Discussion}

\subsection{The Relative CL Intensity-Time Profile}

The behavior of the CL reaction, carried out in the absence and presence of emodin, was tested using $5.0 \times 10^{-8} \mathrm{~mol} \cdot \mathrm{L}^{-1} \mathrm{Mb}$ and $2.5 \times 10^{-5} \mathrm{~mol} \cdot \mathrm{L}^{-1}$ luminol in $2.5 \times 10^{-2} \mathrm{~mol} \cdot \mathrm{L}^{-1} \mathrm{NaOH}$ solution. It can be seen from Figure 3 that CL intensity reaches the maximum at $8 \mathrm{~s}$ after sampling and vanishes within $25 \mathrm{~s}$; the CL evidently decreases with the increasing concentration of emodin.

\subsection{Effect of Luminol, $\mathrm{Mb}$, and $\mathrm{NaOH}$ Concentration}

Under different concentrations of luminol from $1.0 \times 10^{-6}$ to $1.0 \times 10^{-4} \mathrm{~mol} \cdot \mathrm{L}^{-1}$ and $\mathrm{Mb}$ solutions from $1.0 \times 10^{-8}$ to $1.0 \times 10^{-6} \mathrm{~mol} \cdot \mathrm{L}^{-1}$, the $\mathrm{CL}$ intensity was examined. It was found that the $\mathrm{CL}$ intensity arrived at the maximum with $2.5 \times 10^{-5} \mathrm{~mol} \cdot \mathrm{L}^{-1}$ luminol and $5.0 \times 10^{-8} \mathrm{~mol} \cdot \mathrm{L}^{-1} \mathrm{Mb}$. Thus 


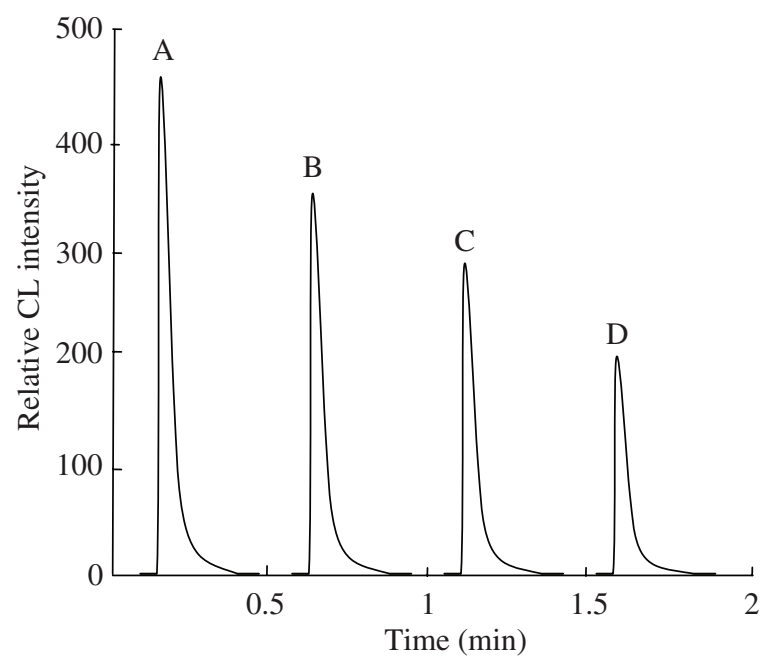

Figure 3: The $\mathrm{CL}$ intensity-time profile. A: luminol-Mb system; $\mathrm{B}$ : luminol-Mb with $10.0 \mathrm{ng} \cdot \mathrm{mL}^{-1}$ emodin system; C: luminol-Mb with $50.0 \mathrm{ng} \cdot \mathrm{mL}^{-1}$ emodin system; D: luminol-Mb with $200.0 \mathrm{ng} \cdot \mathrm{mL}^{-1}$ emodin system.

the luminol solution of $2.5 \times 10^{-5} \mathrm{~mol} \cdot \mathrm{L}^{-1}$ and $\mathrm{Mb}$ solution of $5.0 \times 10^{-8} \mathrm{~mol} \cdot \mathrm{L}^{-1}$ were used in subsequent experiments.

Owing to the nature of the luminol reaction, which is more favorable under alkaline conditions, $\mathrm{NaOH}$ was introduced into the luminol solution to improve the sensitivity of the system. A series of $\mathrm{NaOH}$ solutions with different concentrations from 0.01 to $0.1 \mathrm{~mol} \cdot \mathrm{L}^{-1}$ were tested, respectively. The plot of CL intensity versus $\mathrm{NaOH}$ concentration reached the peak at $2.5 \times 10^{-2} \mathrm{~mol} \cdot \mathrm{L}^{-1}$, and this concentration was employed in the subsequent experiments.

\subsection{Effect of Flow Rate and the Length of Mixing Tubing}

It was found that the CL intensity increased with the increasing flow rate. As a compromise between good precision and lower reagent consumption, $2.0 \mathrm{~mL} \cdot \mathrm{min}^{-1}$ of flow rate on each line was recommended. It was found that $10 \mathrm{~cm}$ mixing tube afforded the best results with the good sensitivity and reproducibility. Accordingly, $10 \mathrm{~cm}$ was selected as the optimum length of mixing tubing.

\subsection{Performance of Presented Method for Emodin Determination}

Under the optimum conditions described, the calibration graph of CL intensity was linear with emodin concentration in the range of $0.5-300 \mathrm{ng} \cdot \mathrm{mL}^{-1}$, given the regression equation $\Delta I_{\mathrm{CL}}=40.29 \mathrm{LnC}+$ $24.96(R=0.9956)$, with detection limit of $0.2 \mathrm{ng} \cdot \mathrm{mL}^{-1}(3 \sigma)$ and RSDs of less than $3.5 \%$. 


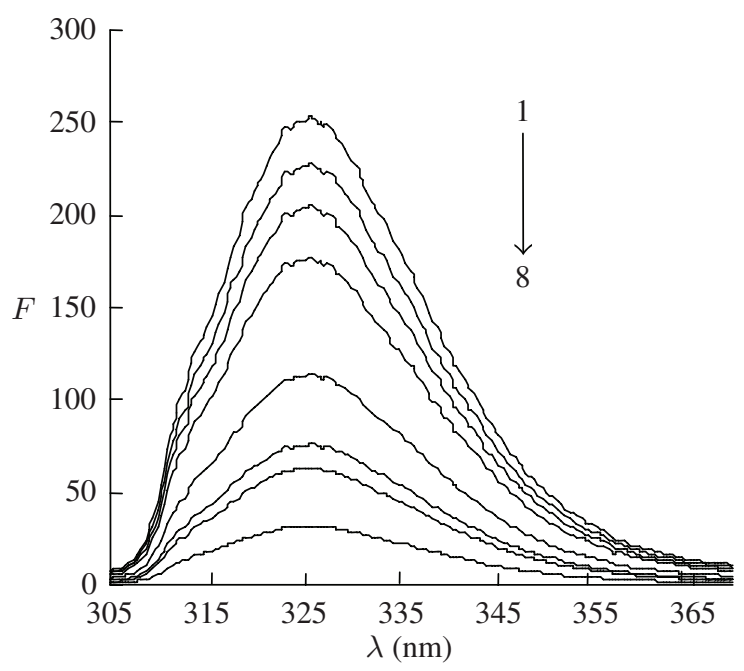

Figure 4: Fluorescence spectra of $\mathrm{Mb}$ with emodin. Concentration: $\mathrm{Mb}: 1.0 \mu \mathrm{mol} \cdot \mathrm{L}^{-1}$; emodin (1-8) 0 , $0.1,0.25,0.50,1.0,2.5,5.0,10.0 \mu \mathrm{mol} \cdot \mathrm{L}^{-1}$.

\subsection{Interference Study}

Under optimum conditions, the effect of foreign substances was investigated by analyzing a standard solution of emodin $\left(50 \mathrm{ng} \cdot \mathrm{mL}^{-1}\right)$ to which increasing amounts of interfering substances were added. The tolerable limit of a foreign species was taken as a relative error of less than $5.0 \%$. The excipients commonly found in the pharmaceutical tablets, such as starch, lactose, cellulose, stearic acid, agar, talc, fructose, and sucrose did not interfere with the determination at tolerable concentrations of $10 \mu \mathrm{g} \cdot \mathrm{mL}^{-1}$, and the tolerable concentrations for other analytes were $5.0 \mu \mathrm{g} \cdot \mathrm{mL}^{-1}$ for $\mathrm{NO}_{3}{ }^{-}, \mathrm{Ac}^{-}$, $\mathrm{I}^{-}, \mathrm{PO}_{4}{ }^{3-}, 2.5 \mu \mathrm{g} \cdot \mathrm{mL}^{-1}$ for $\mathrm{NH}_{4}{ }^{+}, \mathrm{Mg}^{2+}, \mathrm{Ca}^{2+}$, ethanol, glutin, $0.1 \mu \mathrm{g} \cdot \mathrm{mL}^{-1}$ for $\mathrm{Cu}^{2+}, \mathrm{Zn}^{2+}, \mathrm{Cr}^{3+}$ and $\mathrm{Fe}^{2+} / \mathrm{Fe}^{3+}$, respectively.

\subsection{Possible Luminol-Mb-Emodin CL Mechanism}

The possible CL mechanism of luminol-Mb-emodin reaction was discussed by fluorescence and CL. It can be seen that a strong fluorescence emission of $\mathrm{Mb}\left(\lambda_{\mathrm{ex}} / \lambda_{\mathrm{em}, \max }=280 / 326 \mathrm{~nm}\right)$ was quenched evidently in the presence of emodin as shown in Figure 4 . The linear equation was $F_{0} / F=$ $0.04 C_{\text {emodin }}+1.01(R=0.9950)$, where $F_{0}$ and $F$ were the fluorescence intensity of $1.0 \mu \mathrm{mol} \cdot \mathrm{L}^{-1} \mathrm{Mb}$ in the absence and in the presence of emodin with its concentration ranging from 0.1 to $10 \mu \mathrm{mol} \cdot \mathrm{L}^{-1}$. From Stern-Volmer equation [21], the quenching rate constant $K_{\mathrm{q}} 4.05 \times 10^{12} \mathrm{~L} \cdot \mathrm{mol}^{-1} \cdot \mathrm{s}^{-1}$ was obtained which was far greater than the maximum scatter collision-quenching constant of various quenchers with biopolymers $2.0 \times 10^{10} \mathrm{~L} \cdot \mathrm{mol}^{-1} \cdot \mathrm{s}^{-1}$ [22]. It was deduced that the fluorescence quenching of Mb with emodin was initiated by forming the ground-state complex and resulted in the CL intensity of luminol$\mathrm{Mb}$ system decreased as presented in Figure 3. 
Table 1: Results of emodin determination in SANHUANG tablets. ${ }^{a}$

\begin{tabular}{ccccc}
\hline Sample no. & Added/found $\left(\mathrm{ng} \cdot \mathrm{mL}^{-1}\right)$ & RSD $(\%)$ & Recovery (\%) & Content $^{\mathrm{b}}(\%)$ \\
\hline \multirow{2}{*}{1} & $0 / 2.5$ & 2.1 & 105.0 & 0.68 \\
& $2.0 / 4.7$ & 1.5 & & 0.67 \\
2 & $0 / 2.4$ & 2.2 & 96.7 & \\
& $3.0 / 5.3$ & 2.3 & & 0.69 \\
3 & $0 / 2.5$ & 2.0 & 102.0 & 0.67 \\
& $5.0 / 7.6$ & 1.7 & & \\
4 & $0 / 5.6$ & 2.2 & 93.3 & 0.68 \\
5 & $3.0 / 8.3$ & 1.6 & & \\
& $0 / 5.6$ & 2.3 & 94.0 & 0.68 \\
\end{tabular}

a The average of five determinations.

${ }^{\mathrm{b}}$ Per tablet weight: $425 \pm 10 \mathrm{mg}$.

\section{Application}

\subsection{Determination of Emodin in Pharmaceutical Preparations}

Following the procedure detailed above, the proposed method was applied in the determination of emodin in pharmaceutical preparations SANHUANG Tablets. The results were listed in Table 1 showing that the recovery rate ranged from 93.3 to $105.0 \%$ with the RSDs of less than $3.0 \%(n=5)$.

\subsection{Determination of Emodin in Spiked Human Serum Samples}

Emodin in the spiked human serum samples prepared in the experimental section was measured, and the results were summarized in Table 2. It can be seen that the recoveries for the determination of emodin were from 94.0 to $106.3 \%$ and the RSDs were less than $3.5 \%$, confirming the applicability of this method for emodin determination in biological samples.

\section{Conclusion}

A simple and sensitive CL procedure was established based on the quenching effect of emodin on the luminol-Mb CL system for the determination of emodin in pharmaceutical preparations. A comparison of the proposed CL procedure with other methods was presented in Table 3. It is clear that the proposed CL method offers the highest sensitivity and the least reagent consumption for the determination of emodin in pharmaceutical preparations and biofluids. 
Table 2: Results of emodin determination in spiked human serum. ${ }^{\mathrm{a}}$

\begin{tabular}{|c|c|c|c|c|}
\hline Sample no. & $\begin{array}{l}\text { Added/found } \\
\left(\mathrm{ng} \cdot \mathrm{mL}^{-1}\right)\end{array}$ & $\operatorname{RSD}(\%)$ & Recovery (\%) & $\begin{array}{c}\text { By proposed } \\
\text { method/spiked } \\
\left(\mu \mathrm{g} \cdot \mathrm{mL}^{-1}\right)\end{array}$ \\
\hline \multirow{2}{*}{1} & $0 / 19.6$ & 3.3 & \multirow{2}{*}{103.2} & \multirow{2}{*}{$5.15 / 5.0$} \\
\hline & $20.0 / 40.3$ & 2.1 & & \\
\hline \multirow{2}{*}{2} & $0 / 20.2$ & 2.8 & \multirow{2}{*}{99.4} & \multirow{2}{*}{$9.94 / 10.0$} \\
\hline & $30.0 / 50.1$ & 1.9 & & \\
\hline \multirow{2}{*}{3} & $0 / 30.2$ & 2.4 & \multirow{2}{*}{106.3} & \multirow{2}{*}{$15.94 / 15.0$} \\
\hline & $20.0 / 51.3$ & 2.1 & & \\
\hline \multirow{2}{*}{4} & $0 / 50.6$ & 2.2 & \multirow{2}{*}{103.5} & \multirow{2}{*}{$25.87 / 25.0$} \\
\hline & $20.0 / 71.3$ & 1.6 & & \\
\hline \multirow{2}{*}{5} & $0 / 30.1$ & 3.1 & \multirow{2}{*}{94.0} & \multirow{2}{*}{$28.20 / 30.0$} \\
\hline & $20.0 / 48.9$ & 1.5 & & \\
\hline \multirow{2}{*}{6} & $0 / 21.9$ & 3.4 & \multirow{2}{*}{95.8} & \multirow{2}{*}{$38.30 / 40.0$} \\
\hline & $20.0 / 43.9$ & 2.3 & & \\
\hline
\end{tabular}

${ }^{\mathrm{a}}$ The average of five determinations.

Table 3: The comparison of FI-CL and other methods for the determination of emodin.

\begin{tabular}{lccc}
\hline Methods & Concentration range $\left(\mu \mathrm{g} \cdot \mathrm{mL}^{-1}\right)$ & LOD $\left(\mathrm{ng} \cdot \mathrm{mL}^{-1}\right)$ & Refs \\
\hline HPLC & $4.0 \times 10^{-2}-8.0$ & 40.0 & {$[12]$} \\
CE & $1.0 \times 10^{-2}-1.0$ & 3.0 & {$[11]$} \\
ECL & $4.0-1.2 \times 10^{2}$ & $/$ & {$[13]$} \\
UPLC-MS/MS & $2.4 \times 10^{-2}-2.1$ & 2.1 & {$[18]$} \\
EC & $0.3-27.0$ & 81.1 & {$[17]$} \\
UV-Vis & $3.9 \times 10^{-2}-10.0$ & 20.0 & {$[14]$} \\
CL & $5.0 \times 10^{-3}-0.3$ & 2.0 & {$[15]$} \\
\hline
\end{tabular}

\section{Acknowledgments}

The authors gratefully acknowledge the financial support from Key Laboratory of Synthetic and Natural Functional Molecule Chemistry of Ministry of Education, China, Shaanxi Province Nature Science Foundation (no. 2006B05), the NWU Graduate Innovation and Creativity Funds (no. 10YZZ29 and 09YZZ45), and the NWU Graduate Experimental Research Funds, China (no. 09YSY18). 


\section{References}

[1] W. Chen, F. Y. He, and Y. Q. Li, "The apoptosis effect of hispolon from Phellinus linteus (Berkeley \& Curtis) Teng on human epidermoid KB cells," Journal of Ethnopharmacology, vol. 105, no. 1-2, pp. 280-285, 2006.

[2] H. Matsuda, H. Shimoda, T. Morikawa, and M. Yoshikawa, "Phytoestrogens from the roots of Polygonum cuspidatum (Polygonaceae): structure-requirement of hydroxyanthraquinones for estrogenic activity," Bioorganic and Medicinal Chemistry Letters, vol. 11, no. 14, pp. 1839-1842, 2001.

[3] G. Srinivas, S. Babykutty, P. P. Sathiadevan, and P. Srinivas, "Molecular mechanism of emodin action: transition from laxative ingredient to an antitumor agent," Medicinal Research Reviews, vol. 27, no. 5, pp. 591-608, 2007.

[4] L. Liu, J. Zou, X. Liu, L. H. Jiang, and J. Li, "Inhibition of ATP-induced macrophage death by emodin via antagonizing P2X7 receptor," European Journal of Pharmacology, vol. 640, no. 1-3, pp. 15-19, 2010.

[5] J. C. Ko, Y. J. Su, S. T. Lin et al., "Suppression of ERCC1 and Rad51 expression through ERK1/2 inactivation is essential in emodin-mediated cytotoxicity in human non-small cell lung cancer cells," Biochemical Pharmacology, vol. 79, no. 4, pp. 655-664, 2010.

[6] H. Z. Lee, W. H. Yang, M. J. Hour et al., "Photodynamic activity of aloe-emodin induces resensitization of lung cancer cells to anoikis," European Journal of Pharmacology, vol. 648, no. $1-3$, pp. 50-58, 2010.

[7] T. Liu, H. Jin, Q. R. Sun, J. H. Xu, and H. T. Hu, "Neuroprotective effects of emodin in rat cortical neurons against $\beta$-amyloid-induced neurotoxicity," Brain Research, vol. 1347, pp. 149-160, 2010.

[8] C. G. Wang, J. Q. Yang, B. Z. Liu et al., "Anti-tumor activity of emodin against human chronic myelocytic leukemia K562 cell lines in vitro and in vivo," European Journal of Pharmacology, vol. 627, no. 1-3, pp. 33-41, 2010.

[9] H. R. Xiong, J. Luo, W. Hou, H. Xiao, and Z. Q. Yang, “The effect of emodin, an anthraquinone derivative extracted from the roots of Rheum tanguticum, against herpes simplex virus in vitro and in vivo," Journal of Ethnopharmacology, vol. 133, no. 2, pp. 718-723, 2011.

[10] C. M. Hsu, Y. A. Hsu, Y. Tsai et al., "Emodin inhibits the growth of hepatoma cells: finding the common anti-cancer pathway using Huh7, Hep3B, and HepG2 cells," Biochemical and Biophysical Research Communications, vol. 392, no. 4, pp. 473-478, 2010.

[11] R. Mandrioli, L. Mercolini, A. Ferranti, S. Fanali, and M. A. Raggi, "Determination of aloe emodin in Aloe vera extracts and commercial formulations by HPLC with tandem UV absorption and fluorescence detection," Food Chemistry, vol. 126, no. 1, pp. 387-393, 2011.

[12] D. Yan and Y. Ma, "Simultaneous quantification of five anthraquinones in rat plasma by highperformance liquid chromatography with fluorescence detection," Biomedical Chromatography, vol. 21, no. 5, pp. 502-507, 2007.

[13] Z. H. Yin, Q. Xu, Y. Tu, Q. J. Zou, J. H. Yu, and Y. D. Zhao, "Electrocatalysis of emodin at multiwall nanotubes," Bioelectrochemistry, vol. 72, no. 2, pp. 155-160, 2008.

[14] W. Liu, Z. Zheng, X. Liu et al., "Sensitive and robust UPLC-MS/MS method to determine the gender-dependent pharmacokinetics in rats of emodin and its glucuronide," Journal of Pharmaceutical and Biomedical Analysis, vol. 54, no. 5, pp. 1157-1162, 2011.

[15] J. Li, J. Chen, X. L. Zhang, C. H. Lu, and H. H. Yang, "A novel sensitive detection platform for antitumor herbal drug aloe-emodin based on the graphene modified electrode," Talanta, vol. 83, no. 2, pp. 553-558, 2010. 
[16] Y. F. Du, L. M. Xu, and B. H. Yao, "Determination of emodin in rhubarb by spectrophotometry," Chemical Analysis and Meterage, vol. 16, pp. 43-45, 2007.

[17] L. Wang, Z. Zhang, and B. Ye, "Study on the electrochemical behaviour of the anticancer herbal drug emodin," Electrochimica Acta, vol. 51, no. 26, pp. 5961-5965, 2006.

[18] W. Zheng, S. Wang, X. Chen, and Z. Hu, "Identification and determination of active anthraquinones in Chinese teas by micellar electrokinetic capillary chromatography," Biomedical Chromatography, vol. 18, no. 3, pp. 167-172, 2004.

[19] Z. H. Song, L. Wang, and S. Hou, "A study of the chemiluminescence behavior of myoglobin with luminol and its analytical applications," Analytical and Bioanalytical Chemistry, vol. 378, no. 2, pp. 529-535, 2004.

[20] Z. M. Wang and Z. H. Song, "A valuable way for understanding the relationships between lysozyme and cephalosporin analogues by flow injection chemiluminescence," Analyst, vol. 135, no. 10, pp. 2546-2553, 2010.

[21] J. R. Lakowicz, Principles of Fluorescence Spectroscopy, Plenum Press, New York, NY, USA, 1983.

[22] J. R. Lakowicz and G. Weber, "Quenching of fluorescence by oxygen. A probe for structural fluctuations in macromolecules," Biochemistry, vol. 12, no. 21, pp. 4161-4170, 1973. 


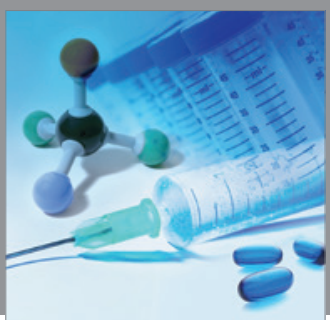

International Journal of

Medicinal Chemistry

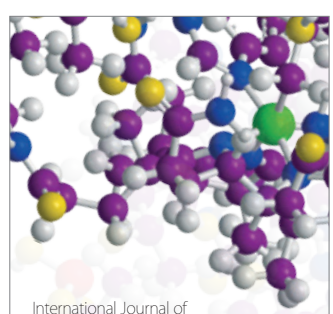

Carbohydrate Chemistry

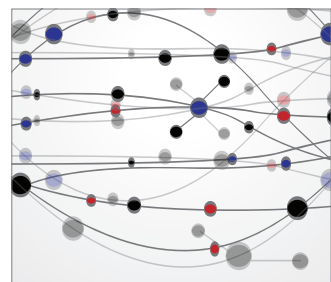

The Scientific World Journal
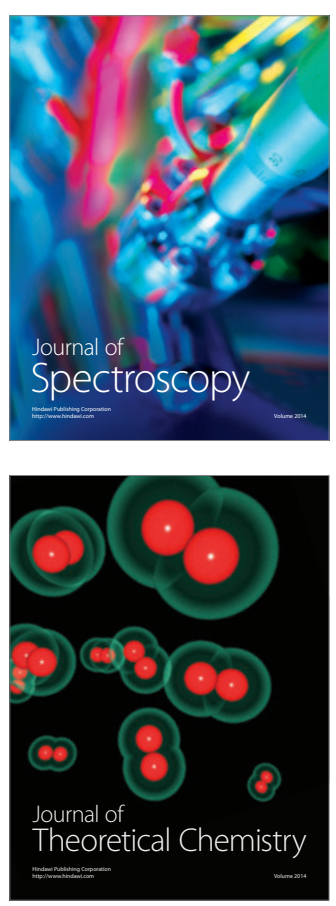
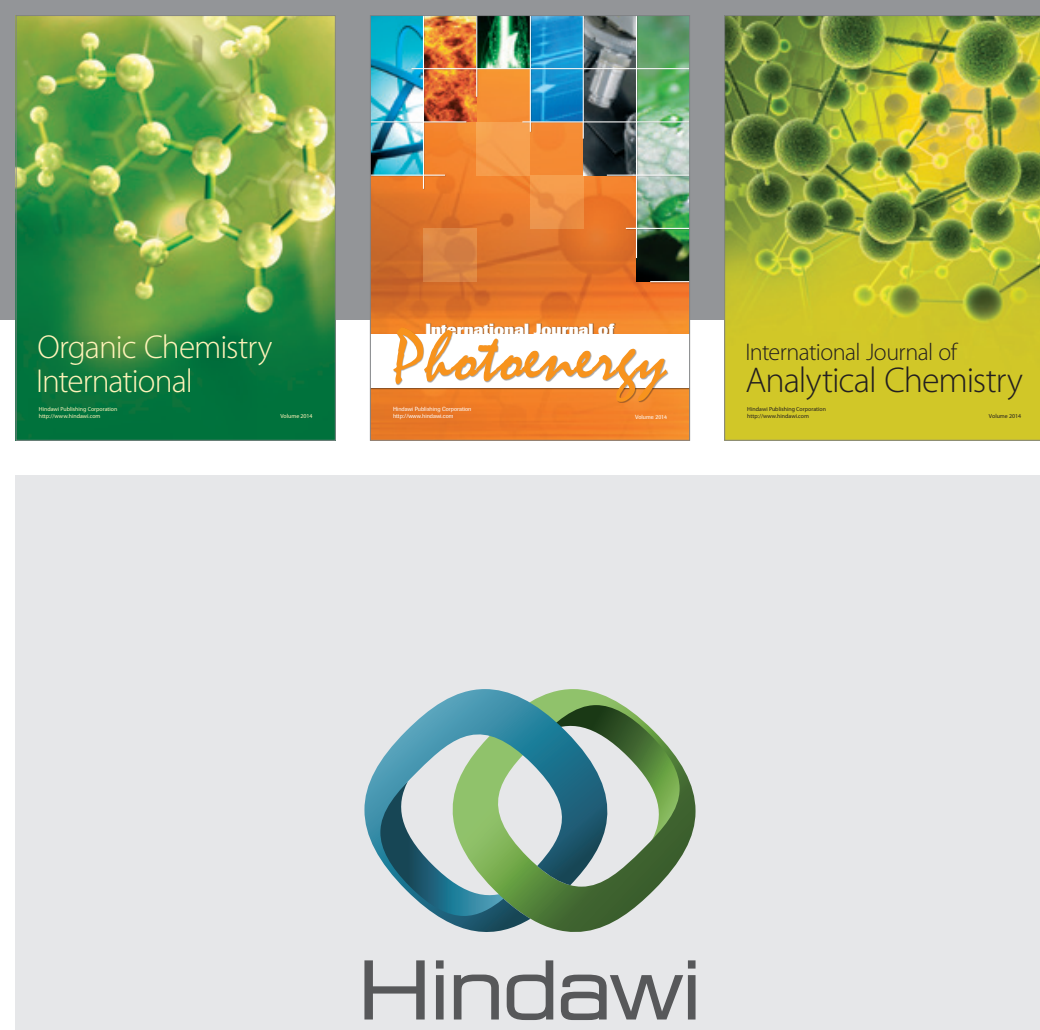

Submit your manuscripts at

http://www.hindawi.com
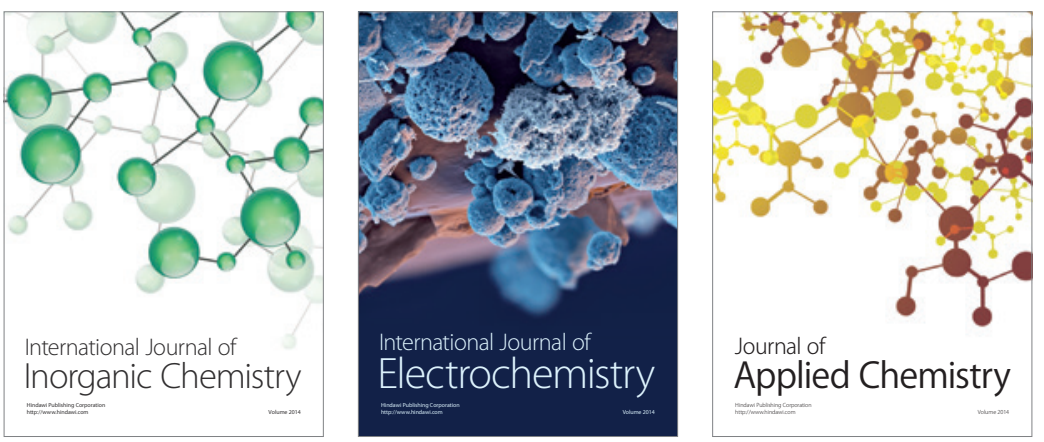

Journal of

Applied Chemistry
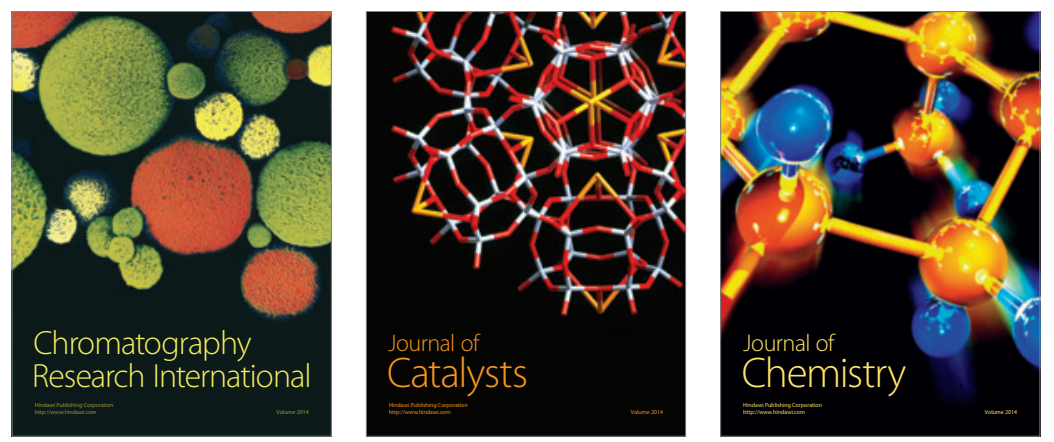
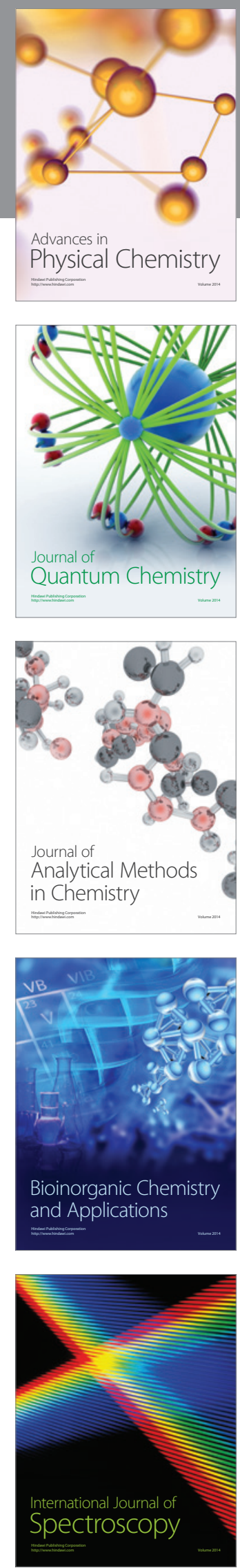